\title{
PSICOPEDAGOGIA E EDUCAÇÃO: DESAFIOS PARA A SAÚDE EMOCIONAL DOS EDUCADORES, POTENCIAL CRIATIVO E O ENSINO POSSÍVEL EM TEMPOS PANDÊMICOS
}

\author{
Mariza P. Porto ${ }^{1}$ \\ CAPSi-Esperança/SMS/Natal/RN
}

\begin{abstract}
RESUMO
No contexto de uma guerra sanitária causada pela pandemia da COVID19, mal-estar e incertezas interpelam, mundialmente, culturas e sociedades exigindo respostas adaptativas ao atual cenário demarcado pelo distanciamento social e novo modus operandi das instituições de ensino, quer sejam de natureza pública ou privada para dar conta dos processos de aprendizagem de seus alunos. Destacamos nesse trabalho, o impacto subjetivo causado pelo enfrentamento dessa pandemia na saúde emocional dos educadores, seus esforços adaptativos e potencial criativo para tornar o ensino possível por meio de videoaulas como tentativa de sustentar a função social da escola e, ao mesmo tempo, atender às necessidades cognitivas e psicoafetivas de seus alunos, mesmo sem vivenciar experiências de formação do professor destinadas para essa realidade. Por fim, apresentamos, à luz da perspectiva psicopedagógica postulada por Alicia Fernández, algumas diretrizes necessárias ao desenvolvimento de uma política de formação profissional continuada para educadores.
\end{abstract}

Palavras-Chave: Pandemia, Processos de Aprendizagem, Impacto Subjetivo, Potencial Criativo, Formação do Professor.

PSYCHOPEDAGOGY AND EDUCATION: CHALLENGES FOR THE EMOTIONAL HEALTH OF EDUCATORS, CREATIVE POTENTIAL AND POSSIBLE TEACHING IN PANDEMIC TIMES

\section{ABSTRACT}

In the context of a health war caused by the covid19 pandemic, uneasiness and uncertainties challenge cultures and societies worldwide, demanding adaptive responses to the current scenario marked by social distancing and a new modus operandi for institutions, whether public or private. We highlight in this paper, the subjective impact caused by facing

\footnotetext{
${ }^{1}$ Psicóloga no Centro de Atenção Psicossocial-CAPSi-Esperança/SMS/Natal/RN, Psicanalista de Crianças, Adolescentes e Adultos, Psicopedagoga e Professora no Instituto Bem Te Vi/Natal/RN. Pós-graduada em Psicopedagogia e Saúde Mental pela Universidade Federal do Rio Grande do Norte/UFRN. Formação em Psicanálise pela Sociedade Psicanalítica da Paraíba/SPP. Membro do Grupo Winnicott da Paraíba/GWPB.
} 
this pandemic on the emotional health of educators, their adaptive effortscto make teaching possible through video lessons and as na attempt to sustain the social function of the school and, at the same time, meet the cognitive and psycho-affective needs of their students. Finally, we presente, in light of the psychopedagogical perspective postulated by Alicia Fernández, some necessary guidelines for the development of a continuing professional education policy for educators.

Keywords: Pandemic, Teacher Training, Learning Processes, Creative Potential.

\author{
É pau, é pedra, é o fim do caminho \\ É um resto de toco, é um pouco sozinho... \\ São as águas de março fechando o verão \\ É a promessa de vida no teu coração. \\ Tom Jobim
}

Era março do ano de 2020, mês alusivo à mulher, ao golpe militar de 1964, sendo também o mês de registro do primeiro caso de adoecimento em decorrência da COVID19 no estado do Rio Grande do Norte (região da minha cidade natal) e da primeira morte em território brasileiro, mais especificamente, no Estado de São Paulo ocasionada pelos efeitos deletérios da contaminação pelo coronavírus.

Passados alguns dias após esses momentos fatídicos, não tardou para recebermos das autoridades sanitárias, locais e governamentais, uma espécie de "toque de recolhimento". Sinal de advertência esse que nos chegou não por meio do fazer soar sirenes; mas, de um modo bem particular, como ato público e político, fomos todos, imediatamente, conclamados a renunciarmos à convivência comunitária, a evitarmos aglomerações e a regularmos nosso contato com ambientes externos, respeitando regras de distanciamento social.

Estamos há mais de um ano revivendo uma experiência ímpar e inusitada de resguardo e afastamento de toda ordem ${ }^{1}$, com o intuito de garantir a continuidade de nossa existência em clima de verdadeira apologia pela defesa da vida e da sobrevivência psíquica de cada um de nós. Talvez, antes, nunca tivéssemos vivido, tão intensamente, a necessidade de acolher e acalentar, como também de sermos acolhidos e acalentados por meio de dizeres e mensagens esperançosas como "Distanciamento não é esquecimento, é lembrar de lutar pela vida"; "Fique em casa"; "Tudo isso vai passar"; " É sem sair que sairemos dessa, vamos ficar em casa"; "Estamos bem, nos encontraremos quando tudo isso passar"; "Estamos confinados agora, para podermos nos encontrarmos depois"; "Vamos ficar em casa para que na hora do reencontro não falte ninguém". Cada uma dessas frases transborda sentimentos e afetos de confiabilidade no ambiente, no outro e no futuro próximo para que possamos suportar o tempo necessário de espera, para nos livrarmos da ameaça de aniquilamento que a covid-19 sobrepõe às nossas vidas, quiçá, à nossa espécie.

Desse tempo em que o coronavírus, com suas dimensões microscópicas e onipresente nos ares e nos lares de centena de milhares de brasileiros, pois hoje ultrapassamos à casa dos 18 milhões de infectados e alcançamos mais de meio milhão de mortos apenas em solo brasileiro; jamais, em momento algum de nossa história, pudemos nos imaginar diante de algo tão ínfimo e, ao mesmo tempo, com uma potência grandiosa capaz de tamanha destruição. Somos tomados, então, pelo sentimento de impotência que alimenta a nossa pequenez diante do implacável, sobretudo, quando esse implacável nos remete à morte, às nossas experiências de perdas irreparáveis e à finitude humana.

Convívio restrito à família nuclear, visitações suspensas em casas de parentes, amigos, vizinhança e demais espaços de ambiência social mais ampla como cinemas, shoppings centers, livrarias, cafés, restaurantes, barzinhos, orla marítima etc. 
Onde quer que se encontre cada habitante de nosso planeta, certamente, deve ter algo a dizer sobre as sensações de desânimo, astenia, preocupações, tristezas, expectativas ansiosas, medos, angústias, ansiedades, insônias, exaustão física e emocional. De modo próprio e singular, cada um deve ter experimentado com maior ou menor intensidade alguns desses sinais de mal-estar durante todo esse período de pandemia que estamos atravessando, sem o indício de qualquer vislumbre de brevidade possível. Uma travessia, vale salientar, cujo cenário é de uma guerra sanitária contra um inimigo invisível e que depende dos avanços da ciência para ser vencido e da sustentação do nosso Sistema Único de Saúde/SUS para tratar, sem distinção, os danos e sequelas nas pessoas acometidas pelo agravamento da covid-19.

Não é difícil imaginar, também, quão rápidas e inesperadas mudanças ocorreram no sistema de ensino, ora vigente, exigindo novas configurações de procedimentos, de metodologias de trabaIho e de todo artefato didático-pedagógico para garantir ações educativas e práticas pedagógicas eficientes e de qualidade para o processo de ensino e de aprendizagem do aluno, assim como de seus professores.

Refiro-me aos professores, especialmente, porque não desconhecemos e nem tampouco podemos negar os esforços adaptativos desprendidos por todos esses trabalhadores da educação brasileira para tornar possível o ensino por meio de videoaulas e, ao mesmo tempo, atender às necessidades cognitivas e psicoafetivas de seus alunos. Por isso, a rapidez com a qual essas mudanças no modo de ensinar e de se relacionar com os objetos e as novas ferramentas de conhecimento, associada ao alto grau de exigência no domínio e no manejo com os novos procedimentos, além do impacto subjetivo causado pelo enfrentamento dessa pandemia, podem, sem sombra de dúvida, contribuir para provocar alguns abalos na saúde emocional de nossos educadores.

Nos últimos cinco anos, temos dialogado amiúde com equipes de professores tão diversas quanto semelhantes. Constatamos, a partir desses encontros dialógicos, que o professor é alguém que se constrói na trama das relações interpessoais e de identificações com ideais. Logo, se constitui como uma entidade em construção, alguém que está por vir a ser posto que não se nasce professor.

Portanto, tão inteligível quanto irrefutável, é a confirmação de que por trás da imagem real de todo e qualquer professor há uma pessoa, um ser humano em si mesmo. Pessoa humana essa que se estruturou a partir das trocas afetivas estabelecidas nas primeiras relações de apego com o outro primordial que se ocupou de seus primeiríssimos cuidados e, muitas vezes, em sala de aula ocupa uma posição peculiar sempre que realiza um trabalho de subjetivação ${ }^{2}$ ao promover processos de educação, em seu sentido mais amplo ${ }^{3}$, junto aos seus alunos e suas diversidades. Refiro-me, pois, à posição do outro primordial, do outro de cuidado em seus tempos de infância, por meio do qual adota uma postura semelhante da mãe.

Alicia Fernández (1998), psicóloga argentina e renomada psicopedagoga, ao escrever para professores, em um de seus artigos, nos diz que o professor é alguém que ocupa uma posição de destaque na vida de seus alunos como referencial e modelo de pessoa e de profissional. Significa dizer que, de algum modo, todo professor contribui para a construção da imagem do aluno enquanto pessoa e sujeito aprendiz.

\footnotetext{
O professor, além de ensinar e transmitir conhecimentos, produz marcas subjetivas que podem determinar a possibilidade de operar, fazendo emergir a dimensão do sujeito desejante e de conhecimento imbuída em seus alunos. Trata-se, por conseguinte, de todo um trabalho que oferece marcas educativas importantes para orientar 0 destino de seus alunos dentro ou fora da escola.

3 Isto é, à ideia de educação como fato social por meio do qual são transmitidos experiências geracionais, valores e todo o conjunto do patrimônio cultural de determinada sociedade, a fim de que possa ser garantida sua continuidade histórico-social.
} 
No seu entender, as atitudes do professor, quer sejam dentro ou fora da sala de aula, adquirem uma importância significativamente maior para a relação com seus alunos, do que para a transmissão de conhecimentos propriamente dita. O que interessa no jogo do aprender é se o professor dá ou não a seus alunos o direito de mostrar seu pensamento, se o professor oferece ou não oportunidades para desenvolver o seu potencial criativo e a curiosidade imanente em cada um deles e se faz com que seus alunos se envergonhem ou não por, eventualmente, ter cometido algumas falhas.

Como podemos ver, na perspectiva de Alicia Fernández (1998), o professor é visto como um modelo de referência para a construção da subjetividade de seus alunos e, por isso mesmo, deve ser reconhecido como Agente Subjetivante, uma vez que o professor

[...]é a única pessoa que poderá mostrar ao aluno um outro modelo de ser humano distinto daqueles modelos que ele, aluno, encontra na família. (Op. Cit. p.26).

No entanto, pensar a questão da formação do professor, mesmo que seja no contexto de tempos pandêmicos como esses que estamos vivendo, se faz atual e premente aplicar o legado deixado pelos constructos teóricos de Alicia Fernández; sobretudo, porque sua sensibilidade estética e rigor teórico passam pela proposta de ressignificação dos processos de aprendizagem desses profissionais da educação, que consiste em:

1. Considerar a dimensão subjetiva do professor que antes de ser um profissional do ensino, é por excelência, um ser humano, um sujeito que se constitui como tal a partir das relações interpessoais e trocas afetivas.

2. Propiciar condições de aprendizagem aos professores, de modo que eles possam descobrir o prazer de aprender e assim poder ensinar com prazer; (mesmo que seja pelo manejo de novas tecnologias educacionais por meio das quais o ensino remoto está sendo veiculado atualmente).

3. Possibilitar a criação de um espaço onde os professores possam ser reconhecidos como pessoas que pensam e desejam; ou seja, onde possam ser trabalhadas suas capacidades de pensar, de criar e, por intermédio de atividades reflexivas e lúdicas, poderem se encontrar com a imaginação criativa e a moção desejante intrínseca a todo ser humano.

4. Desenvolver qualidades no professor, tais como senso de humor, possibilidades de brincar consigo e com os outros, desenvolver a autocrítica, ter amor/paixão pelo conhecimento e por conhecer.

5. Desenvolver uma ética e estética específica de seu fazer pedagógico; saber a dosagem "certa" do guardar e mostrar o conhecimento.

6. Desenvolver condições para que o professor possa suportar e, ao mesmo tempo, criar espaço para as perguntas dos alunos: promover perguntas e possibilitar ao professor condições para que ele possa se situar ressignificando sempre a função positiva de sua ignorância ou o seu não saber.

Por conseguinte, gostaríamos de ressaltar que o processo de formação de professores, tal como é compreendido e efetivado na perspectiva psicopedagógica, identifica o profissional da educação como ser histórico, social e subjetivo (sujeito de desejo) e, que, ao nosso ver, somente por meio dessa validação é que será possível se delinear uma política de formação profissional de base ou continuada, de maneira a se traçar diretrizes que orientem o fazer pedagógico do edu- 
cador, buscando com isso, promover a aprendizagem e o ensino para a diversidade na dimensão de uma educação inclusiva ao alcance de todos os que compõem o cenário escolar.

Por fim, destacamos que estamos vivendo uma situação da ordem do traumático jamais esperada e sem precedentes. Reportando-nos à psicanálise, descobriremos que o trauma tem essa representação: é de natureza inesperada, da ordem do estranho sem nome, que irrompe como realidade produzindo efeitos arrebatadores e catalisadores de angústia e de todo um mal-estar capaz de ameaçar a integridade psíquica, a saúde emocional de uma pessoa.

Laplanche e Pontalis (1988), discutem a noção de trauma, utilizada por Freud, que considera a existência de dois tempos para produzir o efeito traumático no psiquismo.

O traumatismo [...] supõe sempre a existência de, pelo menos, dois acontecimentos: numa primeira cena chamada de sedução, a criança sofre uma tentativa sexual por parte do adulto, sem que nela dê origem a qualquer excitação sexual; uma segunda cena, aparentemente anódina e passada depois da puberdade, vem evocar a primeira por qualquer traço associativo. É a recordação da primeira que desencadeia um afluxo de excitações sexuais que excede as defesas do ego.

Cabe nos perguntarmos, então, que perigos são esses que esse tempo de pandemia nos coloca à mostra, que elementos da nossa história infantil reverberam em nós no enfrentamento desse cenário de guerra que a pandemia causada pelo coronavirus nos impõem? E, por fim, nos interrogarmos também sobre qual a elaboração psíquica possível para sobrevivermos (no plano físico e psíquico) ao impacto causado pela estranheza de todo esse contexto de surto pandêmico da covid-19?

Portanto, o momento pandêmico que estamos vivendo nos interpela com algumas exigências, a fim de que possamos fazer do impacto que nos causou movimentos e ações rumo à sua travessia. Desse modo, somos convocados a reagir liberando forças, ânimo e coragem; demonstrando a nossa capacidade de resistir e sobreviver, nos utilizando, principalmente, da nossa capacidade de viver criativamente, de acreditar e confiar que dias melhores estão por vir.

Entretanto, se não temos como sairmos indiferentes ou incólumes à realidade impactante instaurada por esse momento pandêmico, que possamos sobreviver aos efeitos de todo esse mal-estar que é capaz de nos provocar, imbuídos de esperança, enquanto crença em um futuro melhor e colocando em marcha a capacidade de criar arraigada à nossa essência, para que possamos sentir que a vida vale a pena ser vivida, tal como dizia Winnicott (2019).

Segundo Winnicott (2019), pediatra e psicanalista inglês, a capacidade de viver criativamente é uma das características que nos torna humanos. Para ele, as experiências de vida podem enriquecer nossos processos criativos que acabam expressando o modo como abordamos a realidade externa e usufruímos de seu legado. A noção de criação aqui mencionada, nada tem a ver com a concepção de obra de arte; faz parte da vida dos seres humanos como uma capacidade pessoal para a vida criativa, diz respeito a impulsos criativos que levam o indivíduo a enxergar $o$ mundo criativamente e faz parte da experiência de se sentir vivo.

Porém, não basta estarmos vivos, dizia Winnicott (1945), sozinhos não temos como sobreviver. A dependência, é a priori, uma condição para a existência humana e para nos tornarmos humanos. Significa dizer que a provisão ambiental da qual desfrutamos na tenra infância cumpre importante papel no processo de amadurecimento emocional e no desenvolvimento da criatividade relacionada à arte de viver.

Por conseguinte, nesses tempos de pandemia, de distanciamento social, de quarentena e de tantas tentativas outras de controle dos efeitos deletérios provocados por um vírus ainda não 
Psicopedagogia E Educação: Desafios Para A Saúde Emocional Dos Educadores, Potencial Criativo E O Ensino Possivel Em Tempos Pandêmicos

erradicado, só resta nos alimentarmos de grandes porções de esperança de vida em nossos corações e lembrarmos sempre do que nos escreveu Rubem Alves (2001) ao dizer:

Sim, eu quero viver muitos anos mais. Mas, não a qualquer preço. Quero viver enquanto estiver acesa, em mim, a capacidade de me comover diante da beleza. A comoção diante da beleza tem o nome de "alegria", mesmo quando as lágrimas escorrem pela face. A alegria e a tristeza são boas amigas.

\section{Referências}

ALVES, R. As cores do crepúsculo: A estética do envelhecer. Campinas, SP: Papirus, 2001.

FERNÁNDEZ, A. A inteligência aprisionada: abordagem psicopedagógica clínica da criança e sua família. Porto Alegre: Artes Médicas, 1991.

. Os professores devem buscar a ressignificação de sua aprendizagem. In: Revista Pátio: revista pedagógica, Porto Alegre, no 4, p. 26-28, fev./abr., 1998.

Fonte: JHU ( JHU CSSE COVID-19 ). Acesso em 27 jun. 2021.

GATTI, B. Os professores e suas identidades: e desvelamento da heterogeneidade. In: Caderno de Pesquisa, São Paulo, n 98, p. 85-90, agosto, 1996.

LAPLANCHE, J. e PONTALIS, J. B. Vocabulário da Psicanálise. São Paulo/SP: Livraria Martins Fontes Editora LTDA, 1988.

SCOZ, B. et al. (org.). (Por) uma educação com alma: a objetividade e a subjetividade nos processos de ensino/aprendizagem. Petrópolis, RJ: Vozes, 2000.

WINNICOTT, Donald W. O desenvolvimento emocional primitivo. In: Da Pediatria à Psicanálise: obras escolhidas. Tradução de Davy Bogomoletz. Rio de Janeiro: Imago Editora, 2000.

O brincar e a realidade. Trad. Breno Longhi. Revisão técnica de Leopoldo Fulgêncio. São Paulo: Ubu Editora, 2019. 